\title{
Reduction of radiation exposure to patients in the follow-up of shockwave lithotripsy
}

\author{
J. TALATI, S. KHAN, R. BIYABANI, R.A. KHAN, I. NAZ, F. ABBAS and N.-P. BUCHHOLZ \\ Urology Unit, Department of Surgery, The Aga Khan University, Karachi, Pakistan
}

Objectives To assess, in patients undergoing extracorporeal shock wave lithotripsy (ESWL), if a policy of using unilateral X-rays of the kidney, ureter and bladder (hemi-KUB) whenever possible and appropriate during diagnosis and follow-up, was successful in reducing the radiation exposure associated with ESWL.

Patients and methods Two groups of patients of statistically comparable size and demography were assessed retrospectively before and after the implementation of the policy. All had undergone ESWL for radio-opaque upper urinary tract stones and all were finally rendered stone-free. The number and type of all radiological procedures from initial diagnosis of the stone to documented stone-free status were recorded and the dose calculated.

Results The appropriate use of hemi-KUB X-rays resulted in a significant mean reduction of radiation exposure after treatment of $2.28 \mathrm{mSv}$ per patient $(P<0.05)$. Furthermore, as expected, the radiation dose was clearly but not closely correlated with stone size $(r=0.419)$.

Conclusions The appropriate use of hemi-KUB X-rays during the follow-up after ESWL is a simple and effective way of significantly reducing the radiation exposure of such patients.

Keywords Extracorporeal shock wave lithotripsy, X-ray, radiation exposure, control

\section{Introduction}

Patients undergoing ESWL for urinary stone are exposed to radiation in two ways. First, most lithotripters use Xray monitoring to locate the stone, and several studies have examined such exposure [1-5]. Second, a far larger dose of radiation is received by the patient before and after ESWL, during the initial diagnosis of stone disease and in the follow-up to monitor the success of therapy. To our knowledge, there are no studies addressing this issue.

Besides natural background radiation, medical applications represent the second most intense source of radiation exposure in humans [6]. An exposure of $1 \mathrm{mSv}$ is equivalent to 6 months natural background radiation, but IVU causes a mean radiation exposure of $4.6 \mathrm{mSv}$ to the patient [7]. This radiation exposure has a risk of somatic and genetic long-term complications [6,8-10]. Therefore, there is a unanimous demand to keep radiation levels 'as low as reasonably achievable' [6].

Following these recommendations, a policy was implemented in our institution in 1995 to minimize the exposure to X-rays in the follow-up of patients who underwent ESWL. Whenever adequate, a unilateral Xray of the kidney, ureter and bladder (hemi-KUB), or a bladder X-ray only during the follow-up of a pre-vesical stone, were to be used. This study determined whether

Accepted for publication 22 November 1999 the implementation of the policy was efficient and if the radiation exposure of the patient was reduced.

\section{Patients and methods}

The records of a representative group of consecutive patients undergoing ESWL before (group 1) and after (group 2) implementation of the policy were analysed retrospectively. Group 1 included 78 patients (60 males and 18 females, mean age 38.4 years, range 5-70) treated between October 1994 and March 1995, and group 2 comprised 67 patients ( 52 males and 15 females, mean age 40.3 years, range 21-73) treated between October 1995 and March 1996. All patients were treated with the Dornier MPL $900{ }^{\circledR}$ (Dornier GmBh, Germany) under continuous ultrasonographic guidance with the patients lightly sedated. A mean of 4000 shock waves were delivered at $14-20 \mathrm{kV}$. All patients had one or several stones in either the kidney, PUJ or proximal ureter. Patients were not selected for stone number, size or type. Only those patients who were referred to and followed up in our institution, and were stone-free after ESWL, were included so that it was certain that all X-ray exposure from diagnosis to stone-free status was recorded accurately. Also recorded were the patient's age and sex, the location, size and number of the stone(s), and the number and type of IVU and X-rays undergone before and after ESWL in each patient. Patients who had bladder 
X-rays taken before ESWL were not considered. The mean radiation dosages for the respective groups were calculated according to published recommendations and expressed as milliSeiverts $(1 \mathrm{mSv}=1 \mathrm{~mJ} / \mathrm{kg})$ [7]. Typical doses are: for IVU, $4.6 \mathrm{mSv}$; full KUB X-ray, $1.5 \mathrm{mSv}$; hemi-KUB X-ray, $0.75 \mathrm{mSv}$; and a bladder X-ray, 1.0 $\mathrm{mSv}$.

The two groups were then compared for demographic and radiation data. The correlation for all patients between the stone surface area (SSA) and radiation dose was calculated. Differences were assessed using Student's $t$-test, with $P<0.05$ considered to indicate a significant difference.

\section{Results}

The characteristics of the stones in both groups are shown in Table 1. Of the 78 patients in group 1, $70(90 \%)$ underwent IVU before ESWL; in three of the patients IVU was necessary on two occasions. In those patients not undergoing IVU, the stone was diagnosed by a combination of KUB X-ray and ultrasonography. Forty patients (51\%) needed an additional, confirmatory KUB X-ray before ESWL. The mean total radiation dose per patient before treatment is shown in Table 1. After treatment, 273 control KUB X-rays were taken in 77 patients; one patient was assessed using ultrasonography alone. The total mean radiation dose after treatment (from ESWL until declared stone-free) is also shown in Table 1, with the total radiation dose (from initial diagnosis, through ESWL to stone-free status).

In group 2, 65 patients (97\%) underwent IVU for diagnosis; in one patient, an additional IVU was needed.
In addition, 24 patients needed 26 KUB-X-rays before ESWL. The radiation doses before and after ESWL are also given in Table 1. From ESWL to the last assessment (confirmation of stone-free status), 49 patients still underwent 109 full KUB X-rays. In addition, 65 hemiKUB X-rays were taken in 37 patients. There were no significant differences in age, sex distribution, stone localization, stone number, stones diameters and SSA (all $P>0.05$ ) between the groups.

The radiation dose before ESWL was not significantly different between the groups $(P>0.05)$, but there were significantly fewer full KUB X-rays and more hemi-KUB X-rays (both $P<0.05$ ) in group 2 . The dose after ESWL and consequently the total radiation dose per patient were both significantly reduced in group $2(P<0.05)$, with a mean reduction of $2.28 \mathrm{mSv} /$ patient (Table 1). There was a clear correlation between SSA and radiation dose for all patients $(r=0.419)$ (Fig. 1).

\section{Discussion}

There is continuing concern about the somatic and genetic effects of radiation exposure in medicine; such effects have not yet been fully measured in humans, although animal studies indicate that they may occur [6]. Especially in urogenital diagnostics and treatment, radiation sensitive organs are either exposed or sufficiently nearby to risk exposure [11]. The primary concern about delayed somatic changes is radiationinduced malignant disease [6]. The risk for fatal radiation-induced cancer is estimated as the dose equivalent $(\mathrm{mSv}) \times 0.0004$ [9]. The individual medical radiation exposure for the population in Germany was

Table 1 The characteristics of the stones and the radiation doses per patient before and after ESWL

\begin{tabular}{lcc}
\hline Characteristic & Group 1 & Group 2 \\
\hline Stone location, $n(\%)$ & $39(50)$ & $36(54)$ \\
Kidney & $31(39)$ & $25(37)$ \\
PUJ & $9(11)$ & $6(9)$ \\
Proximal ureter & $34(43)$ & $37(55)$ \\
Right side & $12.6(5.8,2-33)$ & $12.0(6.2,4-35)$ \\
Mean (sD, range) stone size (mm) & $8.8(4.3,2-20)$ & $8.1(4.3,2-20)$ \\
Longitudinal diameter & $128(113,15-500)$ & $118(102,8-525)$ \\
Transverse diameter & $66(84)$ & $61(91.5)$ \\
SSA (mm ${ }^{2}$ ) & $9(11)$ & $5(7)$ \\
Patients, n (\%), with & $4(5)$ & $1(1.5)$ \\
1 stone & & $5.18(1.32,1.5-10.7)$ \\
2 stones & $5.38(2.05,0-12.2)$ & $3.43(2.12,0-4)^{*}$ \\
$>2$ stones & $5.78(3.89,0-18)$ & $8.66(2.43,2.25-14.35)^{*}$ \\
Mean (sD, range) radiation dose (mSv) & $11.09(4.73,3-27.2)$ & \\
Before ESWL & & \\
After ESWL & & \\
Total &
\end{tabular}

${ }^{*} P<0.05 ;$ SSA, stone surface area, LD $\times$ TD. 


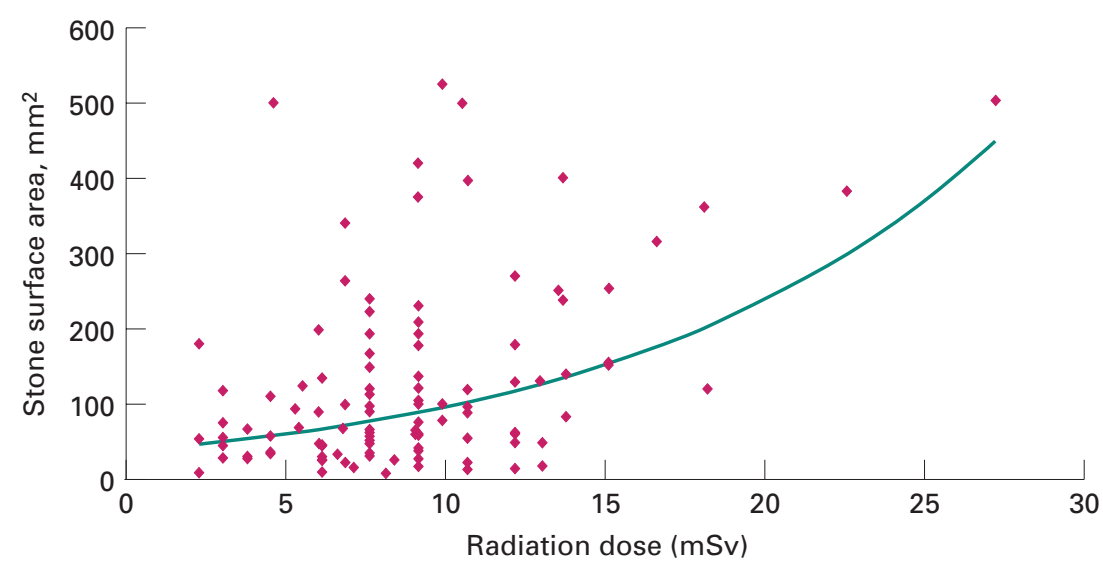

Fig. 1. The correlation between stone size and total radiation exposure in patients undergoing ESWL $(r=0.419)$. estimated at $1-2 \mathrm{mSv} / \mathrm{year}$, which would reduce the mean life-span by 20-40 days. Although this mean value seems negligible [8], the dose to individuals can be much higher. Unnecessary medical radiation exposure is believed to cause 100-250 cancer fatalities per year in the UK alone [10].

Although radiation exposure and its possible reduction during ESWL treatment have been evaluated previously [1-5], to our knowledge there has been no attempt to determine the mean radiation exposure of a patient during diagnosis and assessment after stone fragmentation. The total mean dose during ESWL using an X-ray monitored machine has been estimated at $0.75 \mathrm{mSv}$ [4]. This corresponds to one hemi-KUB X-ray and seems negligible. In contrast, most of the exposure occurs during IVU and conventional radiography before and after ESWL.

In the present study, the radiation dose during treatment was not relevant, as the lithotripter used ultrasonographic monitoring. Although patients were limited to those with upper urinary tract stones (to standardise the radiographs required) the patients were not selected for stone type, number or size, or associated variations in treatment. It was thus intended that the patients were representative of those usually presenting with stones, and comparable with patients in other parts of the world [12]. In the present analysis, common practice in radiation prevention was followed by using standardized dose-equivalents per patient [6,7]; these are known for most adult radiation procedures [13].

Most of the present patients underwent IVU before ESWL; this is standard practice worldwide. Additional KUB radiographs may be necessary, especially if there is some delay before ESWL. As most stones can be assessed after ESWL by X-ray, the patient's exposure can only be reduced by only exposing the affected side. The implementation of this policy was successful; the number of full KUB X-rays was reduced significantly and replaced by hemi-KUB X-rays. This significantly decreased the mean radiation exposure after ESWL by $2.28 \mathrm{mSv} /$ patient, which corresponds to more than one year's mean medical radiation exposure [8], and to 14 months of natural background radiation. This occurred despite the compliance of the prescribing doctors being less than perfect; with increased compliance the reduction could be greater. Radiation exposure increases with stone burden during ESWL [3]; a larger stone requires longer treatment, with possibly more associated X-rays. This was confirmed by the correlation between stone size and radiation dose for all patients.

Therefore, the implementation of a policy to reduce conventional radiographic exposure by using limitedexposure films was effective. It is a simple method to reduce patient radiation exposure, with no loss of information.

\section{References}

1 Griffith DP, Gleeson MG, Politis G, Glaze S. Effectiveness of radiation control program for Dornier HM3 lithotriptor. Urology 1989; 33: 20-5

2 Chen WC, Lee YH, Chen MT, Huang JK, Chang LS. Factors influencing radiation exposure during the extracorporeal shock wave lithotripsy. Scand J Urol Nephrol 1991; 25: 223-6

3 Carter HB, Naslund EB, Riehle Ra Jr Variables influencing radiation exposure during extracorporeal shock wave lithotripsy. Review of 298 treatments. Urology 1987; 30: 546-50

4 Huda W, Bews J, Saydak AP. Radiation doses in extracorporeal shock wave lithotripsy. Br J Radiol 1989; 62: 921-6

5 Bush WH, Jones D, Gibbons RP. Radiation dose to patient and personnel during extracorporeal shock wave lithotripsy. J Urol 1987; 138: 716-9

6 Bushong SC. Radiation protection. In Ballinger PW, ed. Radiographic Positions and Radiologic Procedures. St. Louis: Mosby, 1986: 15

7 RCR Working Party. Minimising radiation dose. In Royal College of Radiologists, ed. Making the Best Use of a 
Department of Clinical Radiology: Guidelines for Doctors London, 1993: 10-1

8 Reiners C. Radiation exposure in diagnostic nuclear medicine: risk comparisons on the basis of effective doses. Nuklearmedizin 1993; 32: 47-51

9 Warren-Forward HM, Haddaway MJ, McCall IW. Risk assessment for diagnostic X-ray examinations in the West Midlands Health Authority. Br J Radiol 1995; 68: 1264

10 Quinn AD, Taylor CG, Sabharwal T, Sikdar T. Radiation protection awareness of non-radiologists. Br J Radiol 1997; 70: 102-6

11 Almen A, Mattsson S. The radiation dose to children from $\mathrm{X}$-ray examinations of the pelvis and the urinary tract. Br J Radiol 1995; 68: 604-13

12 Talati J, Shah T, Memon A et al. Extracorporeal shock wave lithotripsy for urinary tract stones using MPL 9000 spark gap technology and ultrasound monitoring. J Urol 1991; 146: 1482-6

13 Moser E, Schober O. Required dose of imaging systems nuclear medicine. Radiologe 1994; 34: 202-11

\section{Authors}

J. Talati, MBBS, FRCS, Professor and Chairman.

S. Khan, MBBS, Resident.

R. Biyabani, MBBS, FCPS, Senior Instructor.

R.A. Khan, MBBS, Lithotripsy Resident.

I. Naz, MBBS, Lithotripsy Resident.

F. Abbas, MD, FRCS, Associate Professor.

N.-P. Buchholz, MBBS, FFMH, Visiting Lecturer.

Correspondence: Dr N.P. Buchholz, Department of Urology, Erasmus University Rotterdam, NL 3015 GD Rotterdam, The Netherlands. E-mail: nielspeter@yahoo.com 